\title{
SHORT RISK BEHAVIOUR KNOWLEDGE INDEX FOR HIV AVERAGE RISK POPULATION OF SEXUAL ACTIVE AGE IN MUNICH, GERMANY
}

\author{
Alexander V. Kuznetsov', Michael Wiseman², Thomas Ruzicka ${ }^{3}$, Stefan A. Zippel ${ }^{1}$, Laura Kuznetsov' \\ ${ }^{1}$ HIVISTI Prevention Research Group, Department of Dermatology and Allergology, Ludwig-Maximilian University, Munich, Germany \\ 2Leibniz Supercomputing Centre of the Bavarian Academy of Sciences and Humanities, Garching, Germany \\ ${ }^{3}$ Department of Dermatology and Allergology, Ludwig-Maximilian University, Munich, Germany
}

\section{SUMMARY}

Purpose: A short HIV/AIDS risk behaviour knowledge index based on questions about HIV transmission and prevention of HIV infection during sexual intercourse and intravenous drug use is proposed and implemented for an HIV average risk population in Munich.

Methods: Knowledge levels about HIVIAIDS risk behaviour was assessed in a group of people $(n=210)$ in sexually active age range of 18-49 years which was at an average risk of contracting HIV. Four questions about HIV transmission by unprotected vaginal, anal, or oral sexual intercourse, and by needle sharing, and two questions about HIV prevention by condom use, and the single use of needles and syringes were chosen from ten others for making a four level risk behaviour knowledge index (HIV/AIDS Transmission through Sex and Intravenous Drug Use, HATSIDU) internally consistent according to Cronbach's alpha.

Results: HATSIDU index (mean 3.0, SD \pm 1.18 ) was not associated ( $p>0.05$ ) with sex and marital status, but depended $(p<0.05$ ) on age, education and social status. General population of Munich in a sexually active age group of 40-49 years, or those without further education or the unemployed, had a significantly lower knowledge of HIV risk behaviour.

Conclusion: The HATSIDU is a simple and usable index for the assessment of HIV/AIDS risk behaviour knowledge in a population with an average risk of HIV infection.

Key words: HIV/AIDS, risk behaviour knowledge

Address for correspondence: A. Kuznetsov, HIV/STI Prevention Research Group, Dept. of Dermatology and Allergology, Ludwig-Maximilian University, Frauenlobstr. 9-11, 80337 Munich, Germany. E-mail: Alexander.kuznetsov@med.uni-muenchen.de

\section{INTRODUCTION}

Knowledge about HIV/AIDS is one usable indirect criterion for the assessment of behavioural risk and preventative behaviour regarding HIV infection. HIV/AIDS knowledge has been investigated in various populations, for example school students (1, 2 ), adolescents (3), migrant farm workers (4), pregnant women (5), the mentally ill (6), and also in a group of intravenous drug users (IDUs) who have a high risk of contracting HIV (7). The HIV/AIDS risk behaviour knowledge scale was first developed by Kelly et al. (1989) (8) using a group of students, and homosexual men (men who have sex with men, MSM).

The assessment of HIV knowledge or HIV risk behaviour knowledge in population is usually performed by summing up correct answers to questions about HIV transmission and prevention according to age, gender, national, social, and educational status in a knowledge score $(4,6,8)$. The summing up of correct answers to questions about the possibility of HIV transmission by sexual intercourse, intravenous drug sharing, from an infected mother to her child, by hand shaking, or by using public places assumes that all questions are of equal significance and the answers fall in the same rank of importance. Therefore, respondents who correctly answered questions about HIV transmission by sex and drug use but gave incorrect answers for questions about kissing and hand shaking, would receive the same summed knowledge score as the respondents who failed in questions about HIV transmission by sex and intravenous drug use but answered correctly on kissing and hand contact, for example. Because of the equality of all items in constructing a summed knowledge score, HIV/AIDS knowledge can be investigated, but it is not really useful for the assessment of risk behaviour knowledge regarding HIV/AIDS. Assessment of risk behaviour knowledge means that ignorance of some risks has more impact on risk behaviour than others. For example, ignorance about condom use cannot be equated with misconceptions about HIV transmission through hairdressing or by the use of public toilets.

Since 2004, 26 European Union/European Economic Area countries with exception of Poland and Estonia have been reporting statistics regarding transmission routes of HIV infection (9). HIV incidence in EU/EEA decreased in 2009 (5.7/100,000 population) compared to $2004(6.5 / 100,000)$ and was accompanied by a $40 \%$ decrease of intravenous transmission of HIV by intravenous drug users (IDUs), but by a $24 \%$ increase in homosexually (MSM) transmitted HIV. The heterosexual HIV transmission rate in this period depends on the reporting country and varies from $38 \%$ to $52 \%$. 
In Germany, HIV transmission in MSM still constituted 70\% and $67 \%$ in 2005, 2009, respectively, of all newly diagnosed infections, followed by heterosexual and intravenous route in $20 \%$ and $9 \%$ in 2005 (10), and $17 \%$ and $3.5 \%$ in 2009 (11), respectively.

In the light of this epidemiological characteristics, the establishment of an HIV behaviour knowledge index which weighted the knowledge about sexual and intravenous transmission routes differently could be important.

In the present work we tested the reliability of questions about HIV transmission and prevention using Cronbach's alpha (12) in an average risk population for HIV infection in Munich, Germany. The most reliable questions were chosen for constructing an HIV/ AIDS risk behaviour knowledge index.

\section{METHODS}

In autumn 2005, 315 consecutive patients present at outpatient clinic in Munich University hospital in a sexually active age range of 18-49 years were asked to complete the anonymous questionnaire. The study population was assumed to be representative of the Munich city population because any Munich citizens could avail the assistance of the clinic without any pre-selection or referral through the General Practitioner and participate in the survey. Any bias of the studied population by participants who could belong to an HIV risk group was excluded because the outpatient clinic does not admit patients with diseases caused or associated with HIV or sexual, urological, gynaecological infections, drug abuse or psychiatric disorders. The questionnaire included topics about social-demography (sex, age, education, marital and social status), and further ten questions about risk behaviour knowledge regarding HIV/AIDS. These questions concerned HIV transmission during unprotected vaginal, anal or oral sexual intercourse, kissing, hairdressing or by sharing needles and syringes, or kitchen utensils, or by using public places such as a toilet, pool, sauna and also about HIV protection using condoms or single use needles and syringes. Three possible answers "yes", "no" and "I do not know" were the choices offered. Both incorrect and "I do not know" answers were pooled as incorrect answers. The reliability of the questions was assessed by Cronbach's alpha and most reliable questions were used for creating an HIV/AIDS risk behaviour knowledge index. The Mann-Whitney U and Kruskal-Wallis tests were used to determine the significance of an HIV/AIDS risk behaviour knowledge index between social-demographic groups of respondents.

This survey was approved by the Ethics Committee of the Medical Faculty of Ludwig-Maximilian University in 2005.

\section{RESULTS}

225 people (71.4\%) agreed to participate in the study, and 210 questionnaires $(66.7 \%)$ were accepted for analysis. Summary statistics for the questions retained in the analysis are presented in Table 1. Due to their low contribution to reliability, questions $5-8$ were dropped (Cronbach's alpha $=0.555$ ) (Table 1). Hence, for the HIV/AIDS risk behaviour knowledge index, only six questions (No's 1-4, 9, and 10 in Table 1) about HIV transmission by vaginal, anal or oral sex, by intravenous drug use, and about HIV protection using condoms, as well as single use needles and
Table 1. Summary statistics for proposed questions $(n=210)$

\begin{tabular}{|l|c|}
\hline Questions (correct answer) & $\begin{array}{c}\text { Answers, mean } \\
(\mathbf{\pm S D})\end{array}$ \\
\hline $\begin{array}{l}\text { 1. Is HIVIAIDS transmissible by vaginal sexual } \\
\text { intercourse? (yes) }\end{array}$ & $0.89(0.31)$ \\
\hline $\begin{array}{l}\text { 2. Is HIVIAIDS transmissible by anal sexual inter- } \\
\text { course? (yes) }\end{array}$ & $0.83(0.37)$ \\
\hline $\begin{array}{l}\text { 3. Is HIVIAIDS transmissible by oral sexual inter- } \\
\text { course? (yes) }\end{array}$ & $0.67(0.47)$ \\
\hline 4. Is HIVIAIDS transmissible by needle sharing? (yes) & $0.97(0.18)$ \\
\hline $\begin{array}{l}\text { 5. Is HIVIAIDS transmissible by sharing of kitchen } \\
\text { utensils? (no) }\end{array}$ & $0.02(0.14)$ \\
\hline $\begin{array}{l}\text { 6. Is HIVIAIDS transmissible by using of public places, } \\
\text { e.g. WC, swimming pool, or sauna? (no) }\end{array}$ & $0.01(0.97)$ \\
\hline 7. Is HIVIAIDS transmissible by kissing? (no) & $0.1(0.30)$ \\
\hline 8. Is HIVIAIDS transmissible by hair dressing? (no) & $0.07(0.25)$ \\
\hline $\begin{array}{l}\text { 9. Can you protect yourself from HIV/AIDS using } \\
\text { condom during sexual intercourse? (yes) }\end{array}$ & $0.98(0.15)$ \\
\hline $\begin{array}{l}\text { 10. Can you protect yourself from HIVIAIDS using } \\
\text { single needles and syringes? (yes) }\end{array}$ & $0.79(0.4)$ \\
\hline
\end{tabular}

SD - standard deviation

syringes, were chosen for constructing a four level HIV/AIDS Transmission through Sex and Intravenous Drug Use (HATSIDU) risk behaviour knowledge index (Table 2). A high level of risk behaviour knowledge, HATSIDU IV, implied that all six questions were answered correctly. Correct answers to questions about sexual HIV transmission and HIV prevention by condom use were assigned as a good HIV/AIDS risk behaviour knowledge, HATSIDU III. This level allows the omission of questions about HIV transmission by needle sharing and about HIV prevention by using single needles. The decision was made due to low prevalence of IDUs in average Western European populations and the decrease in epidemiological impact of parenteral HIV transmission in Western Europe. According to Hamers et al. (2006) (13), in the EU heterosexual HIV transmission comprises $55 \%$ of newly diagnosed HIV infections, homosexual (MSM) transmission accounts for $34 \%$, and transmission by intravenous drug injection only for $10 \%$. Compared to this, the heterosexual HIV transmission comprised $12 \%$ of newly diagnosed HIV infections in Munich in 2005, homosexual (MSM) transmission accounted for $59 \%$ and transmission by intravenous drug injection only for $2 \%$ (14). In consequence, we assumed that ignorance about sexual transmission of HIV infection, or about its prevention by condom use, should have more impact on the risk behaviour regarding HIV/AIDS in the average (non-risk) population than ignorance about HIV transmission by needle and syringe sharing during intravenous drug use, or about prevention by the single use of needles and syringes. Ignorance of the intravenous route of HIV infection does not have any impact on the risk behaviour regarding intravenous drugs (to use or not to use single syringes; to share or not to share syringes) in non-IDUs. Hence we placed the risk behaviour knowledge level higher (HATSIDU III) if the intravenous HIV transmission was not answered correctly and lower, if the correct answers on sexual transmission of HIV and protection rendered by condoms were not supplied (HATSIDU II or I). Of 
Table 2. Composition of HATSIDU index

\begin{tabular}{|c|c|c|c|c|}
\hline & \multicolumn{4}{|c|}{ HATSIDU } \\
\hline & IV & III & II & I \\
\hline Knowledge level & High & Good & Low & Very low \\
\hline Correct answers & ABCDEF & $A B C D(+/-E$ or $F)$ & $\operatorname{ABCD}(+/-E$ or $F)-1$ & $A B C D(+/-E$ or $F)-(>1)$ \\
\hline Possible variants of answers & ABCDEF & $A B C D ; A B C D E ; A B C D F$ & $\begin{array}{c}\text { ABC; ABD; ACD; BCD; } \\
\text { ABCE; ABDE; ACDE; BCDE; } \\
\text { ABCF; ABDF; ACDF; BCDF }\end{array}$ & $\begin{array}{c}\text { AB; AC; AD; } \\
\text { BC; BD; CD; } \\
\text { A; B; C; D; } \\
\text { ABE; ACE; ADE; } \\
\text { BCE; BDE; CDE; } \\
\text { AE; BE; CE; DE; } \\
\text { ABF; ACF; ADF; } \\
\text { BCF; BDF; CDF; } \\
\text { AF; BF; CF; DF }\end{array}$ \\
\hline \multicolumn{5}{|l|}{ Questions } \\
\hline \multicolumn{5}{|c|}{ A: Is HIV/AIDS transmissible by vaginal sexual intercourse? } \\
\hline \multicolumn{5}{|c|}{ B: Is HIVIAIDS transmissible by anal sexual intercourse? } \\
\hline \multicolumn{5}{|c|}{ C: Is HIVIAIDS transmissible by oral sexual intercourse? } \\
\hline \multicolumn{5}{|c|}{ D: Can you protect yourself from HIVIAIDS using condom during sexual intercourse? } \\
\hline \multicolumn{5}{|c|}{ E: Is HIVIAIDS transmissible by needle sharing? } \\
\hline \multicolumn{5}{|c|}{ F: Can you protect yourself from HIVIAIDS using single needles and syringes? } \\
\hline
\end{tabular}

course, this assumption is only possible for a population with a low risk of intravenous drug use, like the Munich population.

A low level of risk behaviour knowledge regarding HIV/ AIDS, HATSIDU II, was assigned if incorrect answers to questions about HIV transmission through sexual intercourse or about HIV protection by condom use were given, because ignorance of one of the ways of sexual HIV transmission or condom use impacts on the risk of HIV infection. The knowledge or lack of intravenous drug use regarding HIV transmission has not been judged here. The wrong answer to questions about vaginal, anal, oral transmission, were counted equally.

A very low level knowledge of HIV risk behaviour, HATSIDU I, was identified, if more than one way of sexual HIV transmission, and/or use of a condom as protection against HIV infection was not given.

HATSIDU IV, III, II and I were presented in $54.8 \%, 6.2 \%$, $23.8 \%$ and $15.2 \%$ respondents $(n=210)$, respectively, with mean of $3.0(\mathrm{SD} \pm 1.18)$. HATSIDU was not associated $(\mathrm{p}>0.05)$ with sex and marital status, but depended $(\mathrm{p}<0.05)$ on age, education and social status.

Respondents aged 30-39 were significantly better informed about HIV/AIDS risk behaviour (mean=3.44) than those aged $18-29$ years $($ mean $=2.94, \mathrm{p}=0.045)$, and $40-49$ years $($ mean $=2.63$, $\mathrm{p}<0.001)$. Respondents with secondary school education (9-10 years of education) were not significantly less well informed about HIV/AIDS risk behaviour (mean=2.55) than those having high school education $(12-13$ years $)($ mean=2.86). In turn, these were less well informed than respondents with professional school/college $($ mean $=3.46, p=0.012)$, or university (mean $=3.46$, $\mathrm{p}<0.001$ ) education. Unemployed participants were significantly less knowledgeable (mean=2.22) in terms of HIV/AIDS risk behaviour than scholars/students (mean $=3.17, \mathrm{p}=0.021$ ), and employees (mean=3.05, $\mathrm{p}=0.027$ ) (Table 3$)$.

\section{DISCUSSION}

We have proposed and implemented a short four level HIV/ AIDS risk behaviour knowledge index (HATSIDU) based on the correct answers to questions about the two most important ways of HIV transmission, sexual intercourse, and intravenous drug use, and also the two most important HIV prevention measures, condom use and the single use of needles. We examined a convenient sample from the general population in a sexually active age group. As to the epidemiological significance of HIV transmission, intravenous drug use was ranked third after homosexual (MSM) and heterosexual transmission in Munich (14), and in the European Union in 2005 (13). Due to this fact, it was possible to investigate the reliability of HATSIDU index and its implementation in a population of average risk such as our group of respondents.

In HATSIDU, the lack of knowledge about HIV transmission by intravenous drug use yields a higher knowledge level than ignorance about sexual HIV transmission. In contrast, the ignorance of HIV transmission via any of the three sexual transmission routes (vaginal, anal and oral) has been counted equally (even if transmission risks are different) and gave lower knowledge index level compared to non-knowledge regarding parenteral transmission. This decision was made because of following facts. HIV transmission through intravenous drug use belongs traditionally to one of the most important infection routes. However, in 2005-2009 this risk in EU/EEA has decreased by 40\% (9) and by 2.5 times in Germany $(10,11)$. It is also obvious that knowledge regarding HIV risk by needle sharing does not play any role in protecting against HIV transmission in the non IDU population.

The determination of real HIV risk during the different sexual routes is very difficult if not-impossible and depends on many factors, e.g. route of transmission, stage of infection and number of T-helper cells, virus load in the blood or other body fluids and 
Table 3. Characteristics of responders and mean HATSIDU index

\begin{tabular}{|c|c|c|c|}
\hline Variable & $n(\%)$ & Mean HATSIDU ( \pm SD) & $p$ value \\
\hline All responders & $210(100)$ & $3.0(1.18)$ & - \\
\hline Gender & & & $0.335^{* *}$ \\
\hline Male & $91(43.3)$ & $3.09(1.16)$ & \\
\hline Female & $119(56.7)$ & $2.93(1.19)$ & \\
\hline Age (years) & & & $<0.001^{*}$ \\
\hline $18-29$ & 79 (37.6) & $2.94(1.21)$ & \\
\hline $30-39$ & $65(31.0)$ & $3.44(0.95)$ & \\
\hline $40-49$ & $66(31.4)$ & $2.63(1.22)$ & \\
\hline Marital status & & & $0.153^{*}$ \\
\hline Single & $85(40.5)$ & $3.0(1.19)$ & \\
\hline Married & $62(29.5)$ & $2.84(1.21)$ & \\
\hline Partnership & $48(22.9)$ & $3.31(1.05)$ & \\
\hline Divorced/ widowed & $15(7.1)$ & $2.73(1.28)$ & \\
\hline Education (years) & & & $<0.001^{*}$ \\
\hline Secondary school (9-10) & $47(22.4)$ & $2.55(1.33)$ & \\
\hline High school (12-13) & $30(14.3)$ & $2.86(1.19)$ & \\
\hline Professional school/College & $90(42.8)$ & $3.46(0.93)$ & \\
\hline University & $43(20.5)$ & $3.46(0.88)$ & \\
\hline Social status\# & & & $0.018^{*}$ \\
\hline Scholar/student & $40(19.7)$ & $3.17(1.08)$ & \\
\hline Employee & $151(74.4)$ & $3.05(1.16)$ & \\
\hline Unemployed & $12(5.9)$ & $2.22(1.35)$ & \\
\hline
\end{tabular}

SD - standard deviation; ${ }^{*}$ Kruskal-Wallis test; ${ }^{* *}$ Mann-Whitney test; ${ }^{*} \mathrm{n}=203$

on the honesty or knowledge of survey participants regarding the number of their sexual contacts or sexual contacts of their partners, or kinds of intercourse etc. The risk of HIV transmission due to oral intercourse seems to be very low (1-2\% in MSM; 15,16 , 17). Nevertheless the facts about high HIV prevalence in semen $(\sim 100 \%)(18,19)$ and saliva $(\sim 100 \%)(18)$ or vaginal fluid $(59 \%)$ (20), higher vulnerability of pharyngeal mucosa to HIV (21), high prevalence of oral intercourses in heterosexuals ( 75-80\%) and its association with risky sexual behaviour (22) as well as ignorance of oral HIV transmission route in populations $(23,24)$ make oral HIV transmission an important, but often underestimated public health issue.

To the best of our knowledge, this is the first HIV/AIDS behaviour knowledge index constructed not as a mean of the sum of correct answers on questions regarding HIV transmission or its prevention as it has been done before $(25,26,27)$, but by weighing different HIV transmission routes according to their epidemiological risk.

Our survey showed that the general population in Munich aged 40-49 years or those without further education after school, or the unemployed, had a significantly lower knowledge of HIV risk behaviour measured by HATSIDU.

The study has some limitations. The population under study could only be assumed to be representative of the Munich city population because a socio-demographic databank of the Munich population does not exist. We still do not know, if a low HIV/AIDS risk knowledge predicts risk of contracting HIV infection or not. Health risk knowledge is important in self-prevention measures, but it alone seems to be inefficient. For example, in former Soviet Union countries suffering from relative high HIV prevalence, risk perception regarding sexual HIV transmission was not a factor in preventing unprotected sex in HIV-positive people before they contracted virus (28), and no association was found between HIV knowledge and non-use of condoms (25).

The HATSIDU is a simple and usable index for the assessment of HIV/AIDS risk behaviour knowledge in a population with an average risk of HIV infection. Further investigation is needed to examine the risk predictability of HATSIDU regarding risk behaviour, for example in a group of non-IDUs with recently diagnosed HIV infection.

\section{Acknowledgements}

This survey is the part of the PhD thesis of Dr. Laura Kuznetsov, MA, MPH, performed at the Medical Faculty of the Ludwig-Maximilian University, Munich, Germany. Dr. Laura Kuznetsov was supported by the Bavarian Elite Research Scholarship from the University of Bavaria Association ("Universität Bayern e.V.").

We thank very much Mr. Simon Broad, BSc, and Mr. Gregor Kelly, BA, MLitt, for the review of the manuscript. 


\section{REFERENCES}

1. Skurnick JH, Johnson RL, Quinones MA, Foster JD, Louria DB. New Jersey high school students' knowledge, attitudes, and behavior regarding AIDS. AIDS Educ Prev. 1991;3(1):21-30.

2. Tapia-Aguirre V, Arillo-Santillán E, Allen B, Angeles-Llerenas A, CruzValdéz A, Lazcano-Ponce E. Associations among condom use, sexual behavior, and knowledge about HIV/AIDS. A study of 13,293 public school students. Arch Med Res. 2004 Jul-Aug;35(4):334-43.

3. Horan PF, DiClemente RJ. HIV knowledge, communication, and risk behaviors among white, Chinese-, and Filipino-American adolescent in a high-prevalence AIDS epicenter: a comparative analysis. Ethn Dis. 1993;3(2):97-105.

4. Ford K, King G, Nerenberg L, Rojo C. Aids knowledge and risk behaviors among Midwest migrant farm workers. AIDS Educ Prev. 2001 Dec;13(6):551-60.

5. Rogers A, Meundi A, Amma A, Rao A, Shetty P, Antony J, et al. HIVrelated knowledge, attitudes, perceived benefits, and risks of HIV testing among pregnant women in rural Southern India. AIDS Patient Care STDS. 2006 Nov;20(11):803-11.

6. Koen L, Uys S, Niehaus DJ, Emsley RA. Negative symptoms and HIV/ AIDS risk-behavior knowledge in schizophrenia. Psychosomatics. 2007 Mar-Apr;48(2):128-34.

7. Longshore D, Hsieh SC, Anglin MD. AIDS knowledge and attitudes among injection drug users: the issue of reliability. AIDS Educ Prev. 1992;4(1):29-40.

8. Kelly JA, St Lawrence JS, Hood HV, Brasfield TL. An objective test of AIDS risk behavior knowledge: scale development, validation, and norms. J Behav Ther Exp Psychiatry. 1989 Sep;20(3):227-34.

9. Eurosurveillance. Likatavicius G, Van de Laar MJW. HIV and AIDS in the European Union, 2009 [Internet]. Stockholm: ECDC; 2010 [updated 2010; cited 2011 March 10]. Available from: http:/www.eurosurveillance. org/ViewArticle.aspx?ArticleId=19737.

10. Robert Koch Institute (RKI). State of the development of HIV epidemiology in Germany. Epidemiologisches Bulletin. 2005;47:437-46. (In German.)

11. Robert Koch Insitute (RKI). HIV infections and AIDS diseases in Germany. Epidemiologisches Bulletin. 2010;22:205-20. (In German.)

12. Cronbach LJ. Coefficient alpha and the internal structure of tests. Psychometrika. 1951;16(2):297-333.

13. Hamers FF, Devaux I, Alix J, Nardone A. HIV/AIDS in Europe: trends and EU-wide priorities. Euro Surveill. 2006 Nov 23;11(11):E061123.1.

14. Robert Koch Institute (RKI). Reports about confirmed positive HIV antibody tests in the Federal Republic of Germany. Epidemiologisches Bulletin. 2006;A:5-15. (In German.)

15. Sullivan PS, Salazar L, Buchbinder S, Sanchez TH. Estimating the proportion of HIV transmissions from main sex partners among men who have sex with men in five US cities. AIDS. 2009 Jun 1;23(9):1153-62.
16. Campo J, Perea MA, del Romero J, Cano J, Hernando V, Bascones A. Oral transmission of HIV, reality or fiction? An update. Oral Dis. 2006 May;12(3):219-28.

17. Baggaley RF, White RG, Boily MC. HIV transmission risk through anal intercourse: systematic review, meta-analysis and implications for HIV prevention. Int J Epidemiol. 2010 Aug;39(4):1048-63.

18. Liuzzi G, Chirianni A, Clementi M, Bagnarelli P, Valenza A, Cataldo PT, et al. Analysis of HIV-1 load in blood, semen and saliva: evidence for different viral compartments in a cross-sectional and longitudinal study. AIDS. 1996 Dec;10(14):F51-6.

19. Pilcher CD, Joaki G, Hoffman IF, Martinson FE, Mapanje C, Stewart PW, et al. Amplified transmission of HIV-1: comparison of HIV-1 concentrations in semen and blood during acute and chronic infection. AIDS. 2007 Aug 20;21(13):1723-30.

20. Kovacs A, Chan LS, Chen ZC, Meyer WA 3rd, Muderspach L, Young M, et al. HIV-1 RNA in plasma and genital tract secretions in women infected with HIV-1. J Acquir Immune Defic Syndr. 1999 Oct 1;22(2):124-31.

21. Moutsopoulos NM, Greenwell-Wild T, Wahl SM. Differential mucosal susceptibility in HIV-1 transmission and infection. Adv Dent Res. 2006 Apr 1;19(1):52-6.

22. Leichliter JS, Chandra A, Liddon N, Fenton KA, Aral SO. Prevalence and correlates of heterosexual anal and oral sex in adolescents and adults in the United States. J Infect Dis. 2007 Dec 15;196(12):1852-9.

23. Kouznetsov L, Kuznetsov AV, Wienecke R, Zippel SA. AIDS awareness among German resettlers from the former Soviet Union: it is time for an immigrant-specific HIV prevention. Eur J Public Health. 2007 Aug;17(4):403-4.

24. Kouznetsov L, Zippel SA, Kuznetsov AV. What is the accurate knowledge of the German population regarding sexual HIV transmission? Int J Public Health. 2009;54(3):193-5.

25. Babikian T, Freier MC, Hopkins GL, DiClemente R, McBride D, Riggs M. An assessment of HIV/AIDS risk in higher education students in Yerevan, Armenia. AIDS Behav. 2004 Mar;8(1):47-61.

26. Goodwin R, Kozlova A, Nizharadze G, Polyakova G. High-risk behaviors and beliefs and knowledge about HIV transmission among school and shelter children in Eastern Europe. Sex Transm Dis. 2004 Nov;31(11):670-5.

27. Pinkerton SD, Dyatlov RV, DiFranceisco W, Benotsch EG, Smirnova TS, Dudko VY, et al. HIV/AIDS knowledge and attitudes of STD clinic attendees in St. Petersburg, Russia. AIDS Behav. 2003 Sep;7(3):221-8.

28. Kouznetsov L, Kuznetsov AV, Zippel SA. Risky sexual behaviour, taboo of HIV/AIDS and HIV-prevention topics: interviews with HIV-positive immigrants from the former Soviet Union. Int J STD AIDS. 2008 Jan;19(1):71-2. 